\title{
The Explanatory Ambitions of Moral Principles
}

\section{Citation}

Berker, Selim. 2018. The Explanatory Ambitions of Moral Principles. Noûs 251 (2018).

\section{Permanent link}

http://nrs.harvard.edu/urn-3:HUL.InstRepos:41426690

\section{Terms of Use}

This article was downloaded from Harvard University's DASH repository, and is made available under the terms and conditions applicable to Open Access Policy Articles, as set forth at http:// nrs.harvard.edu/urn-3:HUL.InstRepos:dash.current.terms-of-use\#OAP

\section{Share Your Story}

The Harvard community has made this article openly available.

Please share how this access benefits you. Submit a story.

Accessibility 


\title{
THE EXPLANATORY AMBITIONS OF MORAL PRINGIPLES
}

\author{
Selim Berker \\ Harvard University
}

\begin{abstract}
Moral properties are explained by other properties. And moral principles tell us about moral properties. How are these two ideas related? In particular, is the truth of a given moral principle part of what explains why a given action has a given moral property? I argue "No." If moral principles are merely concerned with the extension of moral properties across all possible worlds, then they cannot be partial explainers of facts about the instantiation of those properties, since in general necessitation does not suffice for explanation. And if moral principles are themselves about what explains the moral properties under their purview, then by their own lights they are not needed in order to explain those moral properties' instantiation - unless, that is, the principles exhibit an objectionable form of metaphysical circularity. So moral principles cannot explain why individual actions have moral properties. Nor, I also argue, can they explain why certain other factors explain why those actions have the moral properties that they do, or in some other way govern or mediate such first-order explanations of particular moral facts. When it comes to the explanation of an individual action's specific moral features, moral principles are explanatorily idle.
\end{abstract}

\section{Introduction}

One of the most remarkable features of moral properties is that they are, as W. D. Ross used to put it, "resultant" or "consequential" attributes: they are properties that something can have only in virtue of having other properties. ${ }^{1}$ No action is brutely wrong: whenever I do something wrong, there are certain properties of that action (and, perhaps, of other things in the world as well) that make what I do wrong. Moreover, wrongness's resultant or consequential nature has explanatory upshot: the features, whatever they are, that ground the wrongness of what I did also explain why it was wrong. We can view the familiar theoretical options in moral philosophy as offering competing accounts of what those features are: utilitarian versus Rossian versus Kantian versus . . accounts of that in virtue of which right acts are right, blameworthy conduct is blameworthy, deplorable people are deplorable, etc. And usually the advocates of these accounts go about their theorizing by specifying moral principles that are taken to govern the moral properties being studied.

The central question I will be investigating in this essay is this: what exactly is the relationship between moral principles and the explanation of an action's moral properties by other features? This question can take two forms. On the one hand, we can ask whether the explanatory relation between a moral property and other features is something our moral principles aim to capture. Do moral principles contain as part of their content a relation of explanation between the features they specify and the moral properties under their purview? As I will put it, are moral principles explanation-involving? On the other hand, we can ask whether moral principles themselves are some of the items that stand in an explanatory relation to an action's moral properties. Is the truth of a certain moral principle part of what explains why a given action has a given moral property — or, in a variant of this view, part of what explains why certain 
features explain why a given action has a given moral property? As I will put it, are moral principles explanation-serving? The common dictum "Moral principles are explanatory" is ambiguous between these two readings: it might mean that moral principles feature explanatory relations within themselves as part of their content and hence are explanation-involving, or it might mean that moral principles play a special role in the explanation of moral phenomena and hence are explanation-serving.

My own view is that although moral principles are explanation-involving, they are not explanationserving. As this latter claim is the more controversial of the two, defending it will be the primary focus of this essay. I shall argue that there is no distinctive explanatory role for moral principles to play: principles are not partial explainers of the moral properties of individual actions, nor do they explain, govern, or in some other way facilitate the explanation of those properties by other features. This claim might seem surprising, maybe even a bit daft, but I also think it is inevitable, given the natural way we think of the form and content of moral principles when we engage in first-order ethical theorizing, together with some plausible principles about how explanation works. The view to be defended is in some ways the analogue for moral principles of Humeanism about scientific laws. But it is not entirely that: although on the account that I will develop, moral principles can be viewed as mere summaries, they are not summaries of patterns of co-instantiation among moral and non-moral properties; rather they are summaries of the individual explanation relations that obtain between specific instantiations of moral and non-moral properties. When it comes to the moral domain, explanatory relations first emerge among the particular, and from there creep up to the general. ${ }^{2}$

For simplicity's sake, I will primarily be focusing - as I have so far - on the connection between principles and the explanation of those properties of actions that count as moral, but my arguments generalize in all three respects: they also extend to relations rather than properties, to objects of assessment other than actions, and to normative modes of assessment that are not distinctively moral. And although I will mainly be talking about 'principles', much of what I say can be reformulated using the language of 'laws', 'rules', and 'standards' instead. ${ }^{3}$

\section{Glarifying the Issue}

We shall be exploring the relationship between moral principles and the explanation of moral properties. So we should start by asking two questions: what do I mean by 'moral principles'? And what do I mean by 'explanation'?

It will be easiest to take the second question first. When I speak of 'explanation' in this essay, I have in mind a distinctive sort of non-causal 'because'-relation that we can pick out by means of the following sentences:

1. $\quad p$ because $q$.

2. The fact that $p$ obtains in virtue of the fact that $q$, 
and whose converse we can pick out by means of the following sentences:

3. $\quad$ The fact that $q$ makes it the case that $p$.

4. The fact that $q$ grounds the fact that $p$.

In recent years, it has become customary to use the term 'grounding' as the chief way of designating the form of dependence at issue here, but don't let that label mislead you. 'Grounding' is not a technical term referring to a recently discovered relation. It is simply a new name for a familiar, commonplace notion that ordinary folk make use of when they say things like "He can't legally vote because he's only eight years old," and that philosophers make use of when they say things like "An act is pious because it is loved by the gods." While it might perhaps be true that grounding has only regained respectability and itself become an object of sustained philosophical inquiry in the past decade or so, due largely to the pioneering work of Kit Fine, Gideon Rosen, and Jonathan Schaffer, it is not true that the notion was absent from the scene before then. When metaethicists ask whether morality is mind-dependent, they are talking about grounding. When value theorists insist that something has intrinsic value just in case it is valuable in virtue of its intrinsic properties, they are talking about grounding. And when Ross said that moral properties are resultant on other properties, he was talking about grounding. Grounding is not a twenty-first century innovation; it is as old as philosophy itself, and it is difficult to make sense of much of normative inquiry without it. ${ }^{4}$

I should flag some assumptions I will be making about the nature of grounding. Some of these assumptions are undeniable, and others, though deniable, are harmless, since my arguments do not turn on them. First, I assume that grounding is doubly factive: if $p$ because $q$, then $p$, and if $p$ because $q$, then $q$. This assumption is undeniable: falsehoods can't make anything the case, nor can falsehoods be made the case. ${ }^{5}$ Second, I assume that grounding is a relation rather than a connective. This assumption is harmless: everything I say under the assumption that there is a grounding relation can be rephrased in terms of a grounding connective. Third, I assume that the relata of the grounding relation are facts. ${ }^{6}$ This assumption is also harmless, since any metaethical qualms one might have about moral facts should, given the factivity of grounding, go hand-in-hand with metaethical qualms about whether there are instances of the grounding relation in which at least one relatum is moral. ${ }^{7}$ Fourth, I assume that the grounding relation is singular on the side of what-is-grounded and plural on the side of what-does-the-grounding, so that although it is always a single fact that is grounded, sometimes several facts together ground that single fact. This assumption is harmless. Fifth, I assume that there is a distinction between partial and full grounding. This assumption is undeniable. That the ball is crimson fully grounds the fact that it is red, but only partially grounds the fact that it is red and round.

My final assumption requires special comment. I will be assuming that grounding is itself an explanation relation, so that the following is another way of stating (1)-(4): 
5. The fact that $q$ explains the fact that $p$.

This assumption is currently a matter of controversy in the grounding literature. Many in that literaturecall them unionists, because they posit a union between grounding and explanation-accept this assumption, but others - call them separatists, because they separate grounding from explanation - reject it. ${ }^{8}$ I will be siding with the unionists, and hence I will pass freely back and forth between claims phrased using the idiom of grounding ('grounds', 'makes the case', 'in virtue of', and the like) and claims phrased using 'explanation'-talk. However, this assumption of mine is harmless. Even though separatists divide grounding from explanation, they still hold that the two notions are intimately related, usually by committing themselves to a theory of explanation on which individual explanations are always "backed" by a non-explanatory dependence relation, with causal explanations being backed by the causation relation and (at least one species of) non-causal explanation being backed by the grounding relation. ${ }^{9}$ Thus separatists can reinterpret the arguments in this essay as directly telling us about the connection between moral principles and the grounding of moral facts, but as indirectly telling us about the connection between moral principles and the explanation of moral facts, since presumably the only "backing relation" fit to underlie an explanation of a moral fact is the grounding relation. ${ }^{10}$

Let us turn, then, to our other clarificatory question: what do I mean by 'moral principle'? It is customary to distinguish between two types of - or uses for - moral principles: guides that help us figure out what to do on a given occasion, and standards that specify what it takes for a given action on a given occasion to have some moral property or other. ${ }^{11}$ Guides thus play a deliberative role, whereas standards serve our purposes as theoreticians - and, in particular, serve our purposes insofar as we aim to offer explanations of moral phenomena. For that reason, standards are a more natural target for our investigation. So from this point on I will be focusing exclusively on standards, leaving a discussion of the connection, if any, between guides and the explanation of particular moral facts for another occasion.

I will not attempt to carry out the quixotic task of specifying necessary and sufficient conditions for moral principle-hood. Almost everyone agrees that moral principles must be universal, in the sense that they don't make ineliminable reference to any particular person, object, time, or location, but beyond that discord reigns. How general should a moral principle be? Must moral principles be substantive, or can they be merely formal? Is it okay to qualify a moral principle with an other-things-being-equal clause, or to express it as a generic? Rather than engaging with these controversies, my strategy will be to focus on two paradigm instances that should be acceptable as moral principles by all, namely the Principle of Utility and the seven (or maybe six) principles summarizing Ross's seven (or maybe six) prima facie duties. These are the clearest examples of moral principles that we have, and they also represent the best-case scenario for principles with explanatory ambitions.

One issue that will loom large in the arguments to come is this: what is the logical form of moral principles such as these? As it turns out, authors tend to be divided on this issue, although they are rarely 
explicit about this divide. Often such principles are formulated in a purely intensional manner, so that they concern the extension of the relevant moral properties across all possible worlds, like so (where 'PU' is short for 'Principle of Utility', and 'PF' is short for 'Principle of Fidelity'):

$\mathrm{PU}_{i}$. Necessarily, an action is required if and only if it maximizes happiness.

$\mathrm{PF}_{i}$. Necessarily, if an action breaks a promise, then it is prima facie wrong. ${ }^{12}$

Other times, though, authors formulate these principles hyperintensionally, so that they track distinctions that can be made between necessarily co-extensive properties. The most straightforward way of doing so is to include an appeal to grounding in the content of the moral principles, like so:

$\mathrm{PU}_{h}$. Necessarily, an action is required if and only if, and because, it maximizes happiness.

$\mathrm{PF}_{h}$. Necessarily, if an action breaks a promise, then that makes it the case that the action is prima facie wrong. ${ }^{13}$

Indeed, one might think that even when an author explicitly writes down an intensional formulation of the Principle of Utility or of Fidelity, really it is the hyperintensional formulation that is intended.

This divide over how to formulate moral principles raises the first question we can ask about the connection between moral principles and the explanation of moral properties. Hyperintensional moral principles are explanation-involving: they specify features that not just, as a matter of fact, covary with the moral property at issue, but moreover those features that ground and hence explain that moral property. And, although authors are divided in practice on this issue, I don't think there is really much debate here: clearly the hyperintensional formulation of moral principles is to be preferred over the purely intensional formulation. After all, the usual way of characterizing the difference between guides and standards is to say that whereas guides offer us "decision-making procedures," standards provide us with "accounts of what makes right acts right" (Bales 1971, 257, emphasis mine).

So I consider it to be relatively uncontroversial that moral principles are explanation-involving. The more interesting and contentious issue, which shall be our primary focus from here on out, is whether moral principles are explanation-serving. Do moral principles themselves play a distinctive explanatory role, for instance by being part of what explains why a particular action is wrong, or by explaining why other features explain an action's wrongness, or by enabling, governing, or in some way mediating that firstorder explanation of an action's wrongness? I will be arguing that none of these is the case: in my view, moral principles are not - and cannot be - explanation-serving. But in order not to prejudge any issues, I will be arguing that this conclusion follows regardless of whether moral principles are explanation-involving. So, even though I think it is clear that moral principles aspire to capture explanatory relations as part of their content, I will not be assuming that in what follows.

Two last comments before I proceed. First, when I say that moral principles do not have a distinctive explanatory role, the word 'distinctive' here is crucial. I am not claiming that moral principles 


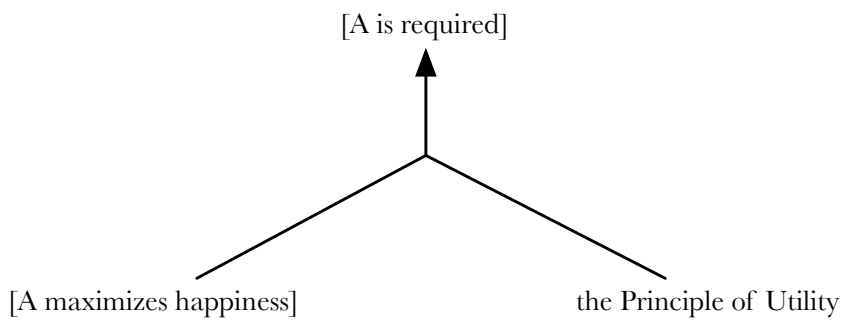

Figure 1. Principles as Partial Grounds.

fail to explain or ground anything. That would be foolish. Everyone must agree that the Principle of Utility, if true, grounds the disjunction of the Principle of Utility and the Continuum Hypothesis, grounds the fact that there is at least one true moral principle, etc. I don't mean to be denying any of that. But these sorts of explanatory roles are trivial: any fact, regardless of its content, can play an equivalent role in making things of this sort the case. What I mean to be ruling out is a special explanatory role for moral principles: an explanatory role that isn't shared by all other truths, or by all truths with the same logical form as a given moral principle.

Second, it will pay to be pedantic in the arguments to come. So I will be adhering to the following conventions. I follow Rosen in using ' $[p]$ ' to denote the fact that $p .{ }^{14}$ When I refer back to an indented sentence that has already been given a label, I use parentheses around the label when I wish to designate the sentence itself, and I use brackets around the label when I wish to designate a fact with the same content as that sentence. Thus ' $\left(\mathrm{PU}_{i}\right)$ ' is a noun phrase referring to the sentence "Necessarily, an action is required if and only if it maximizes happiness," whereas '[ $\left.\mathrm{PU}_{i}\right]$ ' is a noun phrase referring to the fact [Necessarily, an action is required if and only if it maximizes happiness]. ${ }^{15}$

\section{Against Moral Principles as First-Order Grounds}

If moral principles are explanation-serving, and hence play a distinctive role in explaining moral phenomena, what exactly is that role? The most straightforward suggestion is that moral principles are themselves part of what explains why individual actions have the moral properties that they do. Let a particular moral fact be a fact of the form [A has $\mathrm{M}$ ], where $\mathrm{A}$ is a particular action and $\mathrm{M}$ is some moral property. Then if we shift from the language of explanation to the language of grounding (recall my assumption of unionism), the proposal being made is:

Principles as Partial Grounds: Whenever a particular moral fact of the form [A has M] obtains, it is fully grounded in the combination of (i) a general moral principle specifying a connection between $\mathrm{M}$ and some set of non-moral properties or relations and (ii) various particular facts about the instantiation of those non-moral properties or relations.

For example, if $\mathrm{A}$ is an action that is morally required, maybe [A maximizes happiness] and the Principle of Utility together fully ground [A is required]. (See Figure 1.) Or if A is an action that is prima facie wrong, 
maybe [A breaks a promise] and the Principle of Fidelity together fully ground [A is prima facie wrong].

Why does it matter whether Principles as Partial Grounds is true? Here is one significant reason: it might seem that advocates of non-naturalism about the normative are committed to the truth of this thesis. There are many ways of construing the debate between metanormative naturalists and non-naturalists, but on one important way of understanding that debate, it concerns whether the normative facts are - to put it metaphorically - completely tethered in the natural facts. And, although various authors interpret that tethering relation in different ways, with some understanding it as a form of reduction, others as the is-nothing-over-and-above relation, and yet others in terms of property identity, I think we do best to interpret the type of tethering at issue in this debate as the non-causal 'because'-relation that I have been calling 'grounding', and that I have been taking to be a form of explanation. ${ }^{16}$ With their view understood in this way, naturalists about the normative are committed to

Nat. There are normative facts, and every one of them is fully grounded in some natural fact (or plurality of natural facts),

whereas non-naturalists about the normative are committed to

Non. There are normative facts, and at least some of them are not grounded in any fact (or plurality of facts). ${ }^{17}$

But how could (Non) be true? A natural suggestion is to hold that a generalization of Principles as Partial Grounds in which 'moral' is replaced with 'normative' is true, and that it is the true normative principles that are the ungrounded normative facts upon which all other normative facts rest. For this reason, many non-naturalists embrace Principles as Partial Grounds, and it might seem that the very tenability of their metanormative view depends on something like that thesis being true. Moreover, it is not just in the debate over non-naturalism that Principles as Partial Grounds plays an important role: the position is assumed, almost always without argument, by a wide variety of different authors in a wide variety of different contexts. ${ }^{18}$

Nonetheless, I think that Principles as Partial Grounds must be false. My argument against it takes the form of a dilemma. Let us suppose, on the first horn, that we understand the content of moral principles hyperintensionally, as in $\left(\mathrm{PF}_{h}\right)$ and $\left(\mathrm{PU}_{h}\right)$. Then Principles as Partial Grounds faces what I call the Problem of Redundant Grounding, which I formulate here for $\left(\mathrm{PU}_{h}\right)$, although the worry generalizes. We can express the worry as a four-step argument:

P1. The 'because' in $\left(\mathrm{PU}_{h}\right)$ means 'fully because'.

Rationale: Hyperintensional moral principles don't merely state one partial ground among others; rather, they specify all of what is required to ground instantiations of the moral property at issue.

G1. So, if $\left(\mathrm{PU}_{h}\right)$ is true and $\mathrm{A}$ is an action that maximizes happiness, then [A maximizes happiness] on its own fully grounds [A is required]. 


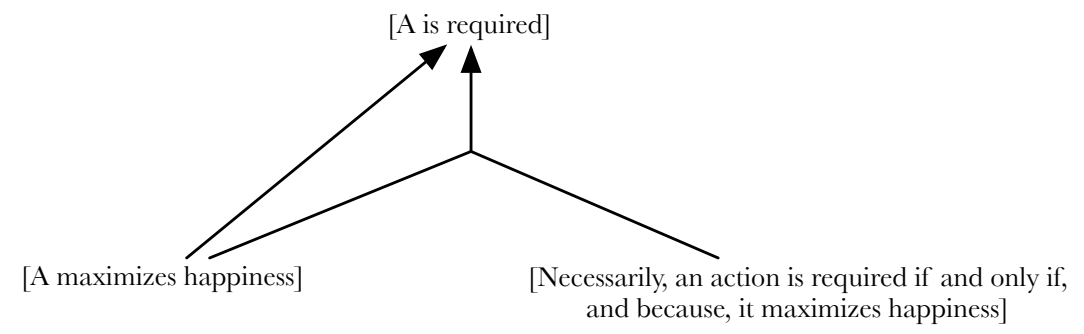

Figure 2. Principles as Partial Grounds, with hyperintensional moral principles.

Rationale: Follows from (P1).

$\mathrm{P} 2$. If $\left[\mathrm{PU}_{h}\right]$ and $\left[\mathrm{A}\right.$ maximizes happiness] together fully ground [A is required], then $\left(\mathrm{PU}_{h}\right)$ is true and $\mathrm{A}$ is an action that maximizes happiness.

Rationale: Given the factivity of grounding, $\left[\mathrm{PU}_{h}\right]$ and [A maximizes happiness] can only make something the case if those two facts obtain.

C2. So, if $\left[\mathrm{PU}_{h}\right]$ and [A maximizes happiness] together fully ground [A is required], then [A maximizes happiness] on its own fully grounds [A is required].

Rationale: Follows from (C1) and (P2).

Thus $\left[\mathrm{PU}_{h}\right]$ can only serve as a partial ground of $[\mathrm{A}$ is required] if it is a redundant partial ground of [A is required]: the fact that together with $\left[\mathrm{PU}_{h}\right.$ ] fully grounds [A is required] suffices on its own to fully ground [A is required]. (See Figure 2, in which the arrows represent relations of full grounding.) But it is implausible that moral principles play their distinctive explanatory role in a redundant way: how can that role be distinctive if it is not needed? ${ }^{19}$

So let us suppose, on the second horn of our dilemma, that we understand the content of moral principles intensionally, as in $\left(\mathrm{PF}_{i}\right)$ and $\left(\mathrm{PU}_{i}\right)$. Then Principles as Partial Grounds faces what I call the Problem of Implausible Grounding. Once we formulate our moral principles intensionally, Principles as Partial Grounds is committed to claims such as the following:

$\mathrm{G}_{1}$. [Action A breaks a promise] and [Necessarily, if an action breaks a promise, then it is prima facie wrong] together fully ground [A is prima facie wrong].

$\mathrm{G}_{2}$. [Action A maximizes happiness] and [Necessarily, an action is required if and only if it maximizes happiness] together fully ground [A is required].

However, these are extremely implausible grounding claims. We don't think the following grounding claims are true:

$\mathrm{G}_{3}$. [Ball B is red and round] and [Necessarily, if an object is red and round, then it is red] together fully ground $[\mathrm{B}$ is red].

$\mathrm{G}_{4}$. [Ball B is colored and extended] and [Necessarily, an object is colored if and only if it is colored and extended] together fully ground [B is colored]. 


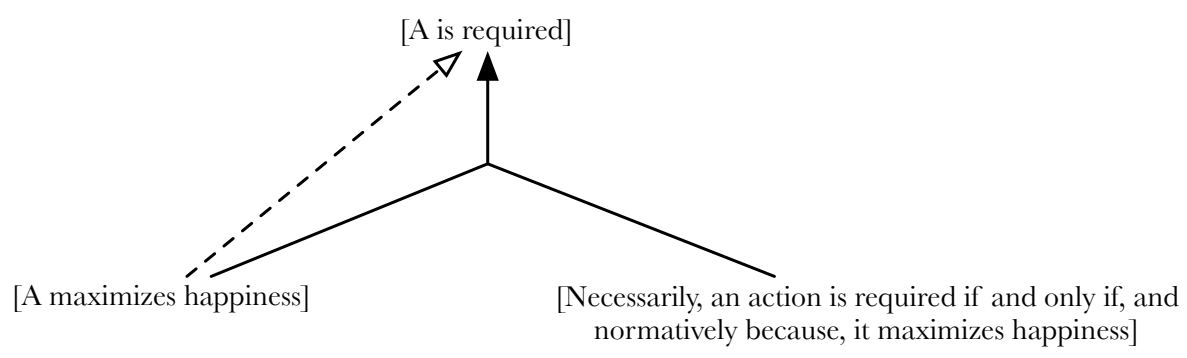

Figure 3. Principles as Partial Grounds, with two grounding relations.

In other words, we don't generally think that one can explain why some object has some property by citing another property of that object and then pointing out that the second property necessitates the first (or that each of these two properties necessitates the other); mere necessitation is the wrong sort of relation to underwrite explanation. So why think that $\left(\mathrm{G}_{1}\right)$ and $\left(\mathrm{G}_{2}\right)$ are true? The underlying thought here is that the sorts of explanatory claims being posited by an advocate of Principles as Partial Grounds only seem plausible if we are implicitly treating the content of our moral principles as not really being purely intensional - and, in particular, only seem plausible if we are implicitly treating our moral principles as featuring a grounding relation in their content. But then we are thrust back on the other horn of our dilemma.

A number of replies to this dilemma suggest themselves. Here are two I take very seriously. First suggestion: perhaps the way out of this dilemma is to embrace grounding pluralism. Maybe, that is, we should follow Fine (2012) in distinguishing between two fundamentally distinct types of grounding, metaphysical grounding and normative grounding, neither of which can be defined in terms of the other, and both of which cannot be defined in terms of a third type of grounding. Then we can interpret the claim made by Principles as Partial Grounds in terms of the metaphysical grounding relation, but formulate the content of our moral principles hyperintensionally in terms of the normative grounding relation, like so:

$\mathrm{PU}_{n}$. Necessarily, an action is required if and only if, and fully normatively because, it maximizes happiness.

$\mathrm{PF}_{n}$. Necessarily, if an action breaks a promise, then that fully normatively makes it the case that the action is prima facie wrong.

Once we distinguish the type of grounding in Principles as Partial Grounds from the type in our moral principles, the Problem of Redundant Grounding disappears. Now all the truth of $\left(\mathrm{PU}_{n}\right)$ together with the fact that $\mathrm{A}$ is an action that maximizes happiness entails is that [A maximizes happiness] on its own fully normatively grounds [A is required], not that it fully metaphysically grounds [A is required]. So, for all I have argued, $\left[\mathrm{PU}_{n}\right]$ can play its role as a partial metaphysical ground of [A is required] in a non-redundant manner: it does not need to team up with another fact that on its own suffices to fully metaphysically ground [A is required]. In short, Figure 2 has now become Figure 3, in which the solid arrow represents a relation 
of full metaphysical grounding, and the dashed arrow represents a relation of full normative grounding. Call this response the grounding-pluralism gambit.

Second suggestion: or perhaps, rather than proliferating types of grounding, the solution is to embrace metaphysical circularity. Maybe, that is, we should include an additional partial ground in our hyperintensional formulation of a given moral principle, namely that principle itself! Then our two examples of principles would become:

$\mathrm{PU}_{c}$. Necessarily, an action, $\mathrm{X}$, is required if and only if, and fully because, the following two facts obtain: [X maximizes happiness] and $\left[\mathrm{PU}_{c}\right]$.

$\mathrm{PF}_{c}$. Necessarily, if an action, $\mathrm{X}$, breaks a promise, then $\left[\mathrm{X}\right.$ breaks a promise] and $\left[\mathrm{PF}_{c}\right]$ together make it the case that $\mathrm{X}$ is prima facie wrong.

Interpreting the content of moral principles in this way allows us to sidestep the Problem of Redundant Grounding, since now each principle no longer says that it itself is not needed in order to fully ground an action's requiredness or prima facie wrongness. Call this response the circularity gambit.

I shall consider these two replies in reverse order, for reasons that will emerge in due course. To keep our discussion manageable, I will only be examining how the replies work with respect to conditional moral principles such as the Principle of Fidelity. This is not a cheat on my part: the additional complexities introduced by the biconditional nature of the Principle of Utility make it, if anything, more difficult — not easier — to pull off theses two responses to my dilemma.

\section{Gircularity to the Rescue?}

On, then, to the circularity gambit. It is tempting to simply dismiss this response out of hand. If that is your attitude, then I am glad for it: feel free to skip to the next section. But for those of us who feel that the circularity gambit has at least some shot of succeeding, I want to spend some time exploring the prospects of avoiding my dilemma by countenancing metaphysical circularity.

Recall that the circularity gambit's central move is to interpret the Principle of Fidelity in such a way that it cites itself as a partial ground of prima facie wrongness, so that we have

$\left[\mathrm{PF}_{c}\right]=\left[\right.$ Necessarily, if an action, $\mathrm{X}$, breaks a promise, then $[\mathrm{X}$ breaks a promise $]$ and $\left[\mathrm{PF}_{c}\right]$ together make it the case that $\mathrm{X}$ is prima facie wrong].

But can there really be a fact of this form? How can a given fact be a fact that is (in part) about what that very fact (in part) grounds? Alas, this question is difficult to assess, because $\left[\mathrm{PF}_{c}\right]$ is such a complicated (would-be) fact. So let us creep up on our quarry by first considering a simpler example with a similar structure. Consider the following alleged fact:

$$
\mathrm{F}=[\mathrm{F} \text { grounds } \mathrm{G}] \text {, }
$$

where $\mathrm{G}$ is some independently specifiable fact. Can it be the case that $\mathrm{F}$ obtains?

It is worth disentangling several different possible sources of concern here. One worry about $\mathrm{F}$ 
might simply be the fact that it is a self-referential fact, where by 'self-referential fact' I mean a fact whose content can be expressed via a sentence that refers to that very fact. However, I don't think that F's selfreferentiality alone is good grounds to deny that it might obtain. Self-reference is a fraught topic, especially in a ground-theoretic context, but it would be overly rash to respond to the difficulties of the topic by imposing a universal ban on self-reference. When it comes to self-referential sentences (rather than facts), we should not take our perplexities over what to say about the liar sentence "This sentence is false" to show that self-referential sentences can never be true, since some undoubtedly are; consider "This sentence has more than two words." Similarly, when it comes to self-referential facts, I think there is at least room to hold that a self-referential fact such as [The content of this fact is expressible with more than two words] might obtain. (And if such facts can't obtain, then all the better for my argument.)20

A second possible concern about $\mathrm{F}$ arises from the presence of a grounding relation within that fact. We introduced $\mathrm{F}$ with the following identity statement:

$$
\mathrm{F}=[\mathrm{F} \text { grounds } \mathrm{G}] \text {. }
$$

Substituting F into itself, as it were, we can rewrite this as

$$
\mathrm{F}=[[\mathrm{F} \text { grounds } \mathrm{G}] \text { grounds } \mathrm{G}] \text {. }
$$

But it is natural to think that no fact of the form [ $\mathrm{X}$ grounds $\mathrm{Y}]$ grounds $\mathrm{Y}]$ can obtain. And if this natural thought is correct, we may conclude that $\mathrm{F}$ does not obtain. Unfortunately, though, that natural thought is mistaken: there are some plausible instances of facts with the form [[X grounds Y] grounds Y]. ${ }^{21}$ Consider the following facts:

$$
\begin{aligned}
& \left.\mathrm{H}_{1}=[[\text { The sky is blue }] \text { grounds [The sky is colored }]\right], \\
& \left.\mathrm{H}_{2}=\left[\mathrm{H}_{1} \text { grounds [Something grounds something }\right]\right], \\
& \mathrm{H}_{3}=\left[\mathrm{H}_{2} \text { grounds [Something grounds something] }\right] .
\end{aligned}
$$

I put forward that all three of these facts obtain. If I ask, "Why does something ground something?" you would be perfectly within your rights to answer, "Because the fact that the sky is blue grounds the fact that it is colored - and also because the very grounding fact I just mentioned grounds the fact that something grounds something." But notice that $\mathrm{H}_{3}$ can be rewritten as $\left[\left[\mathrm{H}_{1}\right.\right.$ grounds [Something grounds something]] grounds [Something grounds something]], and hence is a fact of the form [[X grounds $\mathrm{Y}]$ grounds $\mathrm{Y}$ ]. So some facts of that form can obtain. (And if I am wrong about this, then once again that is all the better for my argument.)

Thus it is not F's self-referentiality on its own that should give us pause, nor merely the fact that $\mathrm{F}$ is a fact of the form [[X grounds $\mathrm{Y}]$ grounds $\mathrm{Y}]$. Rather, what should give us pause is the peculiar way in which these two features of $\mathrm{F}$ interact with one another. If we substitute $\mathrm{F}$ into itself an infinite number of times, the identity statement by which we introduced $\mathrm{F}$ becomes

$$
\mathrm{F}=[[[\ldots \text { grounds } \mathrm{G}] \text { grounds } \mathrm{G}] \text { grounds } \mathrm{G}] \text {. }
$$




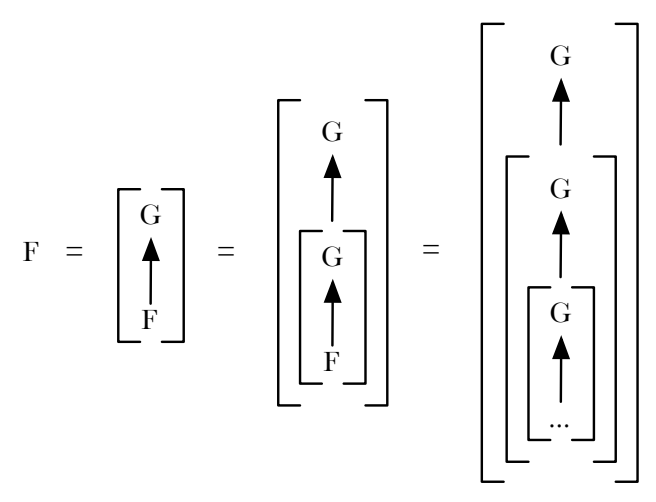

Figure 4. Self-referential fact $F$.

(See Figure 4.) But now we have cause to be worried. How can such an endless quicksand of iterated grounding relations, never leading back to an independent grounder for the entire sequence, be the case? Specifying G helps us see how implausible it is to think that a fact with this form obtains. Suppose we let

$\mathrm{G}=[$ Some self-referential fact makes something the case $]$.

Then we have:

$\mathrm{F}=[\mathrm{F}$ makes it the case that some self-referential fact makes something the case $]$

$=[[\mathrm{F}$ makes it the case that some self-referential fact makes something the case $]$ makes it the case that some self-referential fact makes something the case]

$=[[[\ldots$ makes it the case that some self-referential fact makes something the case $]$ makes it the case that some self-referential fact makes something the case] makes it the case that some selfreferential fact makes something the case].

This choice of $G$ is just about the best-case scenario for a value of $G$ that would allow $F$ to obtain. But even here we should be skeptical. This version of $\mathrm{F}$ is something like a ground-theoretic analogue of the truth-teller sentence "This sentence is true": if $\mathrm{F}$ obtains, then it is a self-referential fact that makes something the case (because all facts make something the case), so it makes it the case that some selfreferential fact makes something the case, and hence its content is true; but if $\mathrm{F}$ does not obtain, then none of this holds, so its content is not true; and there are no independent facts that settle which of these is the case. Just as we should be skeptical that the truth-teller sentence is true, so too should we be skeptical that F obtains.

So much for $\mathrm{F}$; what about $\left[\mathrm{PF}_{c}\right]$, the alleged fact upon which the circularity gambit rests its hopes? Rewording slightly, the version of $\mathrm{F}$ we have just considered is

$\mathrm{F}=[\mathrm{F}$ grounds [Some self-referential fact grounds something $]]$.

If $\mathrm{F}$ does not obtain, then so too does the following not obtain: 
$\mathrm{F}^{*}=$ [If object $\mathrm{O}$ is red, then $\left[\mathrm{O}\right.$ is red] and $\mathrm{F}^{*}$ together ground [O is red, and some self-referential fact partially grounds something]].

(It is not as if sharing the grounding load with another fact is any help in avoiding pernicious circularity.) And if $\mathrm{F}^{*}$ does not obtain, then so too does the following not obtain:

$\mathrm{F}^{* *}=\left[\right.$ Necessarily, if an object, $\mathrm{X}$, is red, then $\left[\mathrm{X}\right.$ is red] and $\mathrm{F}^{* *}$ together ground $[\mathrm{X}$ is red, and some self-referential fact partially grounds something]].

(Sharing the grounding load with another fact and then both quantifying over and necessitating the result is no help, either.) And if $\mathrm{F}^{* *}$ does not obtain, then $\left[\mathrm{PF}_{c}\right]$ does not obtain. (At this point the differences between the two are minimal.) Hence we have no more reason to believe that $\left[\mathrm{PF}_{c}\right]$ might obtain than we have to believe that $\mathrm{F}$ might obtain: the extra logical complexities of the former do not absolve it of the difficulties associated with the latter. The circularity gambit is a no-go.

\section{Grounding Pluralism to the Rescue?}

You might be puzzled as to why I have been devoting so much effort to investigating such a seemingly hopeless reply as the circularity gambit, when a much more plausible response - namely, the groundingpluralism gambit - is available to my opponent. The reason is this: I will now argue that, despite their surface dissimilarities, the circularity and grounding-pluralism gambits are in fact the same objection. Or, more precisely, I will argue that - given a few plausible assumptions - the grounding-pluralism gambit can only avoid the Problem of Implausible Grounding by making itself into a version of the circularity gambit.

This claim of mine might seem surprising. Recall that the grounding-pluralism gambit involves (a) distinguishing between two fundamentally distinct grounding relations, call them 'metaphysical grounding' and 'normative grounding'; (b) insisting that Principles as Partial Grounds is a claim about metaphysical grounding; and (c) insisting that moral principles should be formulated hyperintensionally in terms of normative grounding, like so:

$\mathrm{PF}_{n} . \quad$ Necessarily, if an action breaks a promise, then that fully normatively makes it the case that the action is prima facie wrong.

Where is the metaphysical circularity here?

The answer is that it is not present yet, but also not far away. For as currently formulated, the grounding-pluralism gambit is an inadequate response to my initial dilemma. Suppose A is an action that breaks a promise. Then it follows from the truth of $\left(\mathrm{PF}_{n}\right)$ that

i. [A breaks a promise] fully normatively grounds [A is prima facie wrong].

And it follows from our formulation of Principles as Partial Grounds in terms of metaphysical grounding - which we might as well rename 'Principles as Partial Metaphysical Grounds' - that

ii. $\quad\left[\mathrm{A}\right.$ breaks a promise] and $\left[\mathrm{PF}_{n}\right]$ together fully metaphysically ground [A is prima facie wrong]. 
The key to the grounding-pluralism gambit is that the joint truth of (i) and (ii) does not entail that $\left[\mathrm{PF}_{n}\right]$ is a redundant partial ground of A's prima facie wrongness, for any one type of ground. $\left[\mathrm{PF}_{n}\right]$ is a partial metaphysical ground of [A is prima facie wrong], but not a redundant one, since [A breaks a promise] on its own does not suffice to fully metaphysical ground [A is prima facie wrong]. And $\left[\mathrm{PF}_{n}\right]$ is not even a candidate to be a redundant normative ground of [A is prima facie wrong], since there is no fact that $\left[\mathrm{PF}_{n}\right]$ teams up with to fully normatively ground [A is prima facie wrong].

So the grounding-pluralism gambit has its attraction. However, that response's success crucially depends on the plausibility of (ii). So let us pause to consider that claim a bit. We can rewrite (ii) as

ii*. [A breaks a promise] and [Necessarily, if an action breaks a promise, then that fully normatively makes it the case that the action is prima facie wrong] together fully metaphysically ground [A is prima facie wrong].

However, recall that the advocate of the grounding-pluralism gambit also insists that metaphysical and normative grounding are fundamentally distinct grounding relations: they have as little to do with one another as, say, the relations being a doctoral descendant of and being a blood descendant of do. But then we have no reason at all to believe that $\left(\mathrm{ii}^{*}\right)$ is true. Why would these two utterly different, metaphysically disparate grounding relations interact with one another in the way in which (ii*) claims they do? Such an intimate connection between relations that have fundamentally nothing to do with each other would be an unacceptable mystery. In short, the grounding-pluralism gambit avoids the Problem of Redundant Grounding only by exacerbating the Problem of Implausible Grounding.

The obvious reply is to continue to distinguish between metaphysical and normative grounding, and to continue to formulate Principles as Partial Grounds in terms of the former and moral principles in terms of the latter, but to give up on the Finean assumption that metaphysical and normative grounding are fundamentally distinct grounding relations, where two grounding relations are fundamentally distinct iff they are distinct grounding relations such that neither can be defined in terms of the other, and also such that there is no third grounding relation in terms of which both can be defined.22 In particular, we might take metaphysical and normative grounding to be definitionally linked in such a way that (ii*) ends up being true. The hope is that we can find just enough of a linkage between metaphysical and normative grounding to motivate $\left(\mathrm{ii}^{*}\right)$, without taking the two to be so tightly connected that we resuscitate the Problem of Redundant Grounding.

How do we pull off that trick? It is implausible to hold that metaphysical grounding can be defined in terms of normative grounding, since many instances of metaphysical grounding have nothing to do with normative matters. (For instance, [The sky is blue] metaphysically grounds [The sky is colored], but this is not made the case by anything involving normative grounding.) And one struggles to find a third grounding relation in terms of which both metaphysical and normative grounding can be defined. So presumably we must define normative grounding in terms of metaphysical grounding. The most 
natural way of doing so, while still taking the two relations to be distinct from one another, is as follows:

the suppression proposal: For plurality of facts $\Gamma$ to (fully) normatively ground fact $\mathrm{F}$ is for there to exist a normative principle, $\mathrm{P}$, linking the constituents of the facts that make up $\Gamma$ to the constituents of $\mathrm{F}$ such that $\Gamma$ and $\mathrm{P}$ together (fully) metaphysically ground $\mathrm{F}$.

Hence, on this proposal, normative grounding is metaphysical grounding in which the appeal to a normative principle (whether moral or otherwise) has been suppressed.

In fact, we can say something stronger: it is not just that the suppression proposal is a natural way for the advocate of the grounding-pluralism gambit to avoid my initial criticism of that gambit; rather, given that advocate's commitment to Principles as Partial Metaphysical Grounds, it is difficult to see how any other definition of normative grounding in terms of metaphysical grounding will do, at least when we consider cases involving the normative grounding of particular moral facts by non-moral ones (which are the only cases that need concern us). Suppose $\mathrm{A}$ is an action, $\mathrm{M}$ is a moral property, and $\mathrm{N}$ is a non-moral property such that $[\mathrm{A}$ has $\mathrm{N}]$ fully normatively grounds [A has M]. Since [A has M] is a particular moral fact, it follows from Principles as Partial Metaphysical Grounds that [A has M] is fully metaphysically grounded in a general moral principle specifying a connection between $\mathrm{M}$ and some set of non-moral properties or relations, together with various particular facts about the instantiation of those non-moral properties or relations. And surely at least one set of non-moral properties or relations for which this is the case is the set consisting only of $\mathrm{N}$. But that means that [A has $\mathrm{N}$ ] and a moral principle linking $\mathrm{N}$ and $\mathrm{M}$ fully metaphysically ground [A has M], which is exactly what the suppression proposal says that [A has $\mathrm{M}$ ]'s being fully normatively grounded in [A has $\mathrm{N}$ ] consists in. So at least in the case of the normative grounding of particular moral facts by non-moral ones, Principles as Partial Metaphysical Grounds makes the suppression proposal for how to define that particular instantiation of the normative grounding relation in terms of the metaphysical grounding relation all but inevitable.

But now we have trouble. For the combination of the suppression proposal as an account of the normative grounding of particular moral facts by non-moral ones together with the suggestion that we formulate moral principles in terms of the normative grounding relation inexorably leads to metaphysical circularity in our formulation of moral principles. Here is why. Consider the fact corresponding to our formulation of the Principle of Fidelity in terms of normative grounding:

$\left[\mathrm{PF}_{n}\right]=[\mathrm{Necessarily}$, if an action, $\mathrm{X}$, breaks a promise, then $[\mathrm{X}$ breaks a promise $]$ fully normatively grounds [X is prima facie wrong]].

Given the suppression proposal, and some natural assumptions about metaphysical definition (namely, that facts involving a definiendum are always identical to or at least fully metaphysically grounded in corresponding facts involving its definiens), it follows that $\left[\mathrm{PF}_{n}\right]$ is either identical to or fully metaphysically grounded in the following fact: 
$\left[\mathrm{PF}_{m}\right]=[\mathrm{Necessarily}$, if an action, $\mathrm{X}$, breaks a promise, then $[\mathrm{X}$ breaks a promise $]$ and a normative principle, $\mathrm{P}$, linking promise-breaking to prima facie wrongness together fully metaphysically ground [X is prima facie wrong]].

But what is the principle $\mathrm{P}$ in question? There seem to be only two candidates: $\left[\mathrm{PF}_{m}\right]$ and $\left[\mathrm{PF}_{n}\right]$. On the former possibility, we can rewrite $\left[\mathrm{PF}_{m}\right]$ as

$\left[\mathrm{PF}_{m}\right]=\left[\mathrm{Necessarily}\right.$, if an action, $\mathrm{X}$, breaks a promise, then $[\mathrm{X}$ breaks a promise $]$ and $\left[\mathrm{PF}_{m}\right]$ together fully metaphysically ground [X is prima facie wrong]],

which is just our old friend $\left[\mathrm{PF}_{c}\right]$, i.e. the metaphysically circular version of the Principle of Fidelity that we concluded to be so problematic in the previous section. On the latter possibility, we can rewrite $\left[\mathrm{PF}_{m}\right]$ as

$\left[\mathrm{PF}_{m}\right]=\left[\mathrm{Necessarily}\right.$, if an action, $\mathrm{X}$, breaks a promise, then $[\mathrm{X}$ breaks a promise $]$ and $\left[\mathrm{PF}_{n}\right]$ together fully metaphysically ground [X is prima facie wrong]].

But given that $\left[\mathrm{PF}_{m}\right]$ either is identical to or fully metaphysically grounds $\left[\mathrm{PF}_{n}\right]$, this possibility is also metaphysically circular in a way that is just as problematic as the other possibility. The circularity here is transparent if $\left[\mathrm{PF}_{m}\right]$ is identical to $\left[\mathrm{PF}_{n}\right]$, but it is just as much present if $\left[\mathrm{PF}_{m}\right]$ fully metaphysically grounds $\left[\mathrm{PF}_{n}\right]$. After all, it is not as if we can avoid problematic metaphysical circularity if, instead of taking there to be a self-referential fact of the following form:

$\mathrm{F}=[\mathrm{F}$ fully grounds $\mathrm{G}]$,

instead we take there to be a fact of the following form:

$\mathrm{H}=\left[\mathrm{H}^{*}\right.$ fully grounds $\left.\mathrm{G}\right]$

while also taking it to be the case that $\mathrm{H}$ fully grounds $\mathrm{H}^{*}$.

I conclude that the grounding-pluralism gambit is not really distinct from the circularity gambit after all. In order for the sort of explanatory claim encapsulated in Principles as Partial Metaphysical Grounds to be plausible when we formulate our moral principles hyperintensionally in terms of a normative grounding relation, there must be some sort of a link between metaphysical and normative grounding. And I have argued that this link is enough to re-institute a problematic form of metaphysical circularity in the content of our moral principles. ${ }^{23}$

Indeed, there is a way of viewing my dilemma on which an appeal to metaphysical circularity is precisely what is called for, if one wants to respond to it by grasping the dilemma's hyperintensional horn (as both the circularity and grounding-pluralism gambits attempt to do). If moral principles concerning, say, the rightness of actions are in the business of specifying right-makers, then those principles can only themselves be (partial) right-makers - as Principles as Partial Grounds holds - if they cite themselves as being among the right-makers. To deny this circularity is to invite redundancy. And proliferating rightmaking relations is no help, either, since we can also proliferate our types of principles and run my objection with regard to those principles that encapsulate the type of right-making at issue in Principles as 


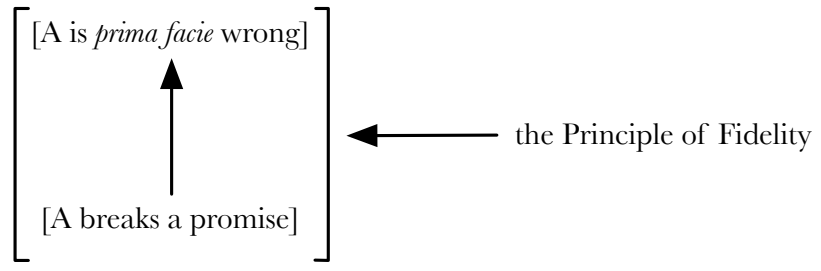

Figure 5. Principles as Meta-Grounds.

Partial Grounds. These considerations lead me to conclude that Principles as Partial Grounds is incompatible with a hyperintensional conception of moral principles. And an intensional conception fares no better: if our moral principles specify mere necessary conditions for rightness, then it is not plausible that either they or the conditions they specify are among the right-makers for actions, since in general necessary conditions are not grounds. Principles as Partial Ground's prospects are looking bleak.

\section{Against Moral Principles as Higher-Order Grounds}

Perhaps, then, we should explore a different way in which moral principles might be explanation-serving. Another natural suggestion is

Principles as Meta-Grounds: Whenever a fact (or plurality of facts) fully grounds a particular moral fact, a general moral principle fully grounds this grounding fact.

For example, maybe the Principle of Utility fully grounds the fact that [Action A maximizes happiness] fully grounds [A is required]. Or maybe Ross's Principle of Fidelity fully grounds the fact that [A breaks a promise] fully grounds [A is prima facie wrong]. (See Figure 5.) Rather than being explainers, moral principles are, on this proposal, meta-explainers: they explain why certain other facts explain particular moral facts. ${ }^{24}$

Although Principles as Meta-Grounds is not as widely accepted as Principles as Partial Grounds, one does encounter it from time to time as an unargued-for background assumption in an author's work. ${ }^{25}$ Moreover, it is a natural fallback position for those who accept my criticisms of that other view.

However, this fallback fares no better than the position it would replace, for Principles as MetaGrounds is just as problematic as Principles as Partial Grounds. Once again my objection takes the form of a dilemma, although this time I press a version of the Problem of Implausible Grounding on both horns. Suppose, on the one hand, we understand the content of moral principles intensionally, as in $\left(\mathrm{PF}_{i}\right)$. Then the grounding claim being made by advocates of Principles as Meta-Grounds is

$\mathrm{G}_{5}$. [Necessarily, if an action breaks a promise, then it is prima facie wrong] grounds [[A breaks a promise] grounds [A is prima facie wrong]],

where A is a particular action, and where from now on 'grounds' means 'fully grounds' unless I specify otherwise. But the following schema is incredibly implausible: 
$\mathrm{G}_{6} . \quad$ Necessarily, if $p$, then $\left.q\right]$ grounds $[[p]$ grounds $[q]]$.

Given that necessitation does not even suffice for grounding, there is no reason to think that grounding facts are in general explained by necessitation facts. And if $\left(\mathrm{G}_{6}\right)$ doesn't hold in general, why think that $\left(\mathrm{G}_{5}\right)$ holds in particular?

Suppose, on the one hand, we understand the content of moral principles hyperintensionally, as in $\left(\mathrm{PF}_{h}\right)$. Then the grounding claim being made by our advocate of Principles as Meta-Grounds is

$\mathrm{G}_{7}$. $\quad$ Necessarily, if an action, $\mathrm{X}$, breaks a promise, then $[\mathrm{X}$ breaks a promise $]$ grounds $[\mathrm{X}$ is prima facie wrong]] grounds [[A breaks a promise] grounds [A is prima facie wrong]],

where again A is some particular action. But this is once again a dubious grounding claim, as we can see by comparing it to

G. [Necessarily, if an object, $\mathrm{Y}$, is black, then [Y is black] grounds [Y is black or blue]] grounds [[B is black] grounds [B is black or blue]],

where B is some particular object. According to both $\left(\mathrm{G}_{7}\right)$ and $\left(\mathrm{G}_{8}\right)$, an indicative conditional that is necessitated and universally generalized grounds the consequent of one of its non-necessitated particular instances. All three of these contrasts are problematic: indicative conditionals do not in general make their consequents the case; ${ }^{26}$ necessity facts do not in general make their non-necessitated contents the case; and universal generalizations do not in general make their instances the case (if anything, the order of explanation is the other way around). So we have no reason to accept either $\left(\mathrm{G}_{7}\right)$ or $\left(\mathrm{G}_{8}\right)$.

Thus I am led to the conclusion that Principles as Meta-Grounds fares no better than Principles as Partial Grounds as an account of the way in which principles might be explanation-serving. The basic problem is that Principles as Meta-Grounds is a proposal about what grounds certain grounding facts, and although the issue of what grounds grounding facts is a vexed topic, ${ }^{27}$ either intensionally or hyperintensionally formulated moral principles are of the wrong form to be the sort of thing that makes it the case that certain facts make some particular moral fact the case.

\section{Essentialism to the Rescue?}

The worry we have just identified for Principles as Meta-Grounds also suggests a way out. If the problem is that Principles as Meta-Grounds makes an implausible claim about what grounds moral grounding facts, maybe the solution is to look at going accounts of the grounds of grounding facts and to customize the content of our moral principles accordingly. In particular, according to one currently popular proposal, it is facts about essences that make the facts about what grounds what the case. ${ }^{28}$ Why does [The ball is black] ground [The ball is black or blue]? Perhaps because it lies in the nature of disjunction that a disjunctive fact is grounded in any of its disjuncts that are the case. And, more generally, perhaps facts of the form $[[p]$ grounds $[q]]$ are always ultimately grounded in facts of the form [It lies in the nature of $x$ that $r]$, for some carefully chosen values of ' $x$ ' and ' $r$ '. But if that's so, then one natural way of trying to save Principles 
as Meta-Grounds is to reformulate the content of our moral principles so that they feature a wide-scope essence operator instead of a wide-scope necessity operator, like so:

$\mathrm{PF}_{e} . \quad$ It lies in the nature of $y$ that if an action breaks a promise, then it is prima facie wrong, where $y=$ action, or promises, or prima facie wrongness, or some combination thereof. Then if we help ourselves to the essentialist account of what grounds grounding facts, our problems for Principles as MetaGrounds evaporate, right?

Wrong. For even if essence facts ground grounding facts, $\left[\mathrm{PF}_{e}\right]$ is not the right sort of essence fact to give us what we want. The advocate of Principles as Meta-Grounds is now asserting

G9. [It lies in the nature of $y$ that if an action breaks a promise, then it is prima facie wrong] grounds [[A breaks a promise] grounds [A is prima facie wrong] ]. ${ }^{29}$

However, this is a highly dubious explanatory claim. Presumably it lies in the nature of conjunction that if $p \& q$, then $p$. But [It lies in the nature of conjunction that if $p \& q$, then $p]$ does not ground $[[p \& q]$ grounds $[p]]$. So why think $\left(\mathrm{G}_{9}\right)$ is true?

In light of this problem, our essentialist might try a different tack. Perhaps we can avoid the objection by inserting a grounding relation into the embedded content of our moral principles, like so:

$\mathrm{PF}_{e}^{*}$. It lies in the nature of $y$ that: if an action, $\mathrm{X}$, breaks a promise, then [X breaks a promise] grounds [X is prima facie wrong].

The suggestion, in other words, is that rather than swapping a necessity operator for an essence operator in $\left(\mathrm{PF}_{i}\right)$, instead we do the same with $\left(\mathrm{PF}_{h}\right)$. But this is no help: $\left(\mathrm{PF}_{e}^{*}\right)$ also leads to implausible grounding claims, if we accept Principles as Meta-Grounds. To explain why, I need to bring in one more piece of machinery, namely a distinction between immediate and mediate grounding. This a standard and intuitive distinction. For instance, [The ball is red] immediately grounds [Something is red] but only mediately grounds [Something is red, or the pencil is yellow]. With this distinction in hand, I put forward the following:

Ess. The only fact devoid of essence operators and higher-order quantifiers that [t is lies in the nature of $x$ that $p]$ immediately grounds is $[p]$.

The 'devoid of essence operators and higher-order quantifiers'-qualifier is needed to handle the claim that [It lies in the nature of $x$ that $p$ ] immediately grounds [Either it lies in the nature of $x$ that $p$, or $q$ ], the claim that [It lies in the nature of $x$ that $p$ ] immediately grounds [There is an operator, $\mathrm{O}$, such that $\mathrm{O}(p)$ ], and other claims of that kind, which I don't mean to deny. My proposal is that, these sorts of logical cases aside, essence facts do all of their grounding work by first grounding the content within the essence operator and then from there grounding other stuff. I am not aware of any plausible counterexamples to (Ess), so I adopt it here as a working hypothesis. ${ }^{30}$

It follows from (Ess) that $\left[\mathrm{PF}_{e}^{*}\right]$ immediately grounds [If an action, $\mathrm{X}$, breaks a promise, then $[\mathrm{X}$ breaks a promise] grounds $\left[\mathrm{X}\right.$ is prima facie wrong]]. Thus if $\left[\mathrm{PF}_{e}^{*}\right]$ is to ground [[A breaks a promise] 
grounds [A is prima facie wrong]], it presumably must be the case that

$\mathrm{G}_{10}$. [If an action, $\mathrm{X}$, breaks a promise, then [X breaks a promise] grounds [X is prima facie wrong]] grounds [[A breaks a promise] grounds [A is prima facie wrong]].

But it is not plausible that a universally-generalized indicative conditional of this sort (even partially) grounds the consequent of one of its instances. So once again the advocate of Principles as Meta-Grounds is committed to a dubious explanatory claim.

This leaves the essentialist with one last hope. Perhaps she should reformulate the content of her moral principle yet again, so that it becomes

$\mathrm{PF}_{e}^{* *}$. It lies in the nature of $y$ that [A breaks a promise] grounds [A is prima facie wrong], where A is some particular action whose prima facie wrongness is being explained. After all, it is perfectly compatible with (Ess) that $\left[\mathrm{PF}_{e}^{* *}\right]$ grounds [[A breaks a promise] grounds [A is prima facie wrong]]. The problem, though, is that $\left(\mathrm{PF}_{e}^{* *}\right)$ is not an acceptable candidate for a moral principle, since it only makes a claim about one individual action, and as such lacks the requisite level of universality that all principles must possess. It is just as problematic for a putative moral "principle" to say only what one particular person should do as it is for a putative moral "principle" to tell us only about the prima-facie-wrong-making features of a single, individual action. This was our one uncontroversial assumption about the content of moral principles: they must be, in this sense, universal (Hare 1972). So, given that the bridge between facts about essence and facts about what grounds the moral must occur at the level of the particular, an essence fact at this transition point cannot be the content of a moral principle. ${ }^{31}$ Moving from necessity operators to essence operators is not a way of salvaging Principles as Meta-Grounds.

\section{Nomic Primitivism to the Rescue?}

It is time for one last response to my various arguments. I have waited until the end to consider this objection because versions of it can be offered in defense of either Principles as Partial Grounds or Principles as Meta-Grounds, and also because the response is similar in spirit to the essentialist gambit we just considered. In pressing my dilemmas against both Principles as Partial Grounds and Principles as Meta-Grounds, I offered the defenders of these proposals two options: either formulate a moral principle such as Ross's Principle of Fidelity intensionally, like so:

$\mathrm{PF}_{i}$. Necessarily, if an action breaks a promise, then it is prima facie wrong, or formulate it hyperintensionally via an appeal to grounding, like so:

$\mathrm{PF}_{h}$. Necessarily, if an action breaks a promise, then that makes it the case that the action is prima facie wrong.

The essentialist views this as a false dilemma: according to her, it is better to formulate the content of the Principle of Fidelity by means of a wide-scope essence operator. During my arguments against this position, I relied on claims about how that essence operator functions in general, in contexts other than 
those involving moral principles and the explanation of particular moral facts. So maybe we can block my arguments by continuing to hold that $\left(\mathrm{PF}_{i}\right)$ versus $\left(\mathrm{PF}_{h}\right)$ represents a false dilemma, but by putting forward an alternative that appeals to an operator that is customized for this particular context and no others. In other words, maybe we can block those arguments by positing that there is a primitive moral-law operator - expressible with the phrase "It is a moral law that" - which does exactly the work we need it to do here, and no other work. Then we could formulate the content of the Principle of Fidelity as follows:

$\mathrm{PF}_{l} . \quad$ It is a moral law that: if an action breaks a promise, then it is prima facie wrong.

Since this operator is regarded as primitive, it is not reducible to an operator involving essence, necessity, or any other notion that might give rise to the problems we encountered earlier. ${ }^{32}$ But this is all compatible with taking our moral-law operator to have certain properties that might be of use to a proponent of the claim that moral principles/laws are explanation-serving. For example, maybe moral laws are "in the business" - to use Schaffer's (2016b) felicitous phrase - of grounding particular moral facts, so that if $\mathrm{A}$ is an action that breaks a promise, the following is the case:

$\mathrm{G}_{11}$. $\left[\mathrm{PF}_{l}\right]$ and [A breaks a promise] together ground [A is prima facie wrong].

Then Principles as Partial Grounds would be true after all. Or maybe moral laws are, rather, in the business of grounding the facts about what grounds particular moral facts, so that we instead have

$\mathrm{G}_{12}$. $\left[\mathrm{PF}_{l}\right]$ grounds [[A breaks a promise] grounds [A is prima facie wrong]].

Then Principles as Meta-Grounds would be true after all.

In fact, on this proposal, a third way in which moral principles might be explanation-serving suggests itself. Maybe there is a sui generis "governing" relation that sometimes (or perhaps always) obtains between a general principle/law (whether moral, metaphysical, or scientific) and a given instantiation of the grounding relation. The rough idea is that, when principle $\mathrm{P}$ governs the grounding of fact $\mathrm{G}$ by fact $\mathrm{F}$, then $\mathrm{P}$ in some sense oversees, underwrites, or mediates (choose your favorite metaphor) the explanatory connection between $\mathrm{F}$ and $\mathrm{G}$. If all of this makes sense, then perhaps moral laws are really in the business of governing the grounding relation between particular moral facts and other facts, so that what we have instead of $\left(\mathrm{G}_{11}\right)$ and $\left(\mathrm{G}_{12}\right)$ is

$\mathrm{G}_{13}$. $\left[\mathrm{PF}_{l}\right]$ governs the grounding of [A is prima facie wrong] by [A breaks a promise].

Then we could defend an alternative to Principles as Partial Grounds and Principles as Meta-Grounds, namely:

Principles as Governors: Whenever a fact (or plurality of facts) fully grounds a particular moral fact, a general moral principle governs this grounding relation.

(See Figure 6, in which the dotted line represents the governing relation.)

What are we to make of these various options? Let us start by considering the version that appeals to nomic primitivism as a way of defending Principles as Partial Grounds. Then it is being claimed that, if 


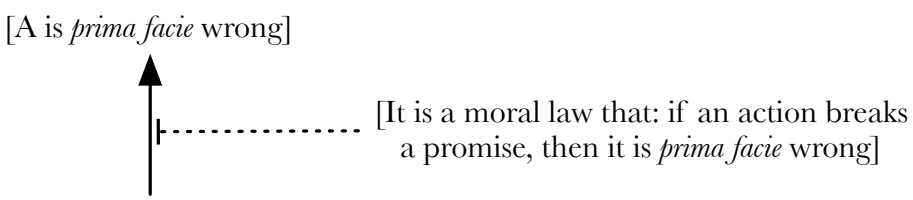

[A breaks a promise]

Figure 6. Principles as Governors.

[It is a moral law that: if an action breaks a promise, then it is prima facie wrong] and [A breaks a promise] obtain, these two facts together fully make it the case that [A is prima facie wrong] also obtains - that's just what moral laws $d o$. But now we can ask: is "It is a moral law that . .." an intensional context, so that if the sentences " $p$ " and " $q$ " necessarily have the same truth value, then "It is a moral law that $p$ " and "It is a moral law that $q$ " do so as well? The answer, of course, is "No," for "If an action breaks a promise, then it is prima facie wrong" and "If an action breaks a promise and is not a rational number, then it is prima facie wrong" have the same truth value in all possible worlds, yet it is absurd to think that [A is not a rational number] ever partially makes it the case that $\mathrm{A}$ is prima facie wrong. Indeed, matters are even worse than that. It is not just that the nomic-primitivist advocate of Principles as Partial Grounds is committed to a few obvious breakdowns of intensionality with regard to the phrase "It is a moral law that . . ." Rather, she is committed to some extremely subtle violations of intensionality. In conversation, we rarely mark a distinction between sentences such as "It is a moral law that if an action is $\phi_{1}$ and $\phi_{2}$, then it is $\psi$ " and "It is a moral law that if an action is $\phi_{1}$, then if it is also $\phi_{2}$, it is $\psi$." But for the sort of nomic primitivist we are considering, there is a crucial difference between these two claims, for the first commits her to $\left[\mathrm{A}\right.$ is $\left.\phi_{1}\right]$, $[\mathrm{A}$ is $\phi_{2}$ ], and the moral law in question together grounding [A is $\psi$ ], whereas the second commits her to [A is $\left.\phi_{1}\right]$ and the moral law together grounding [If $\mathrm{A}$ is $\phi_{2}$, then $\mathrm{A}$ is $\psi$ ].

Thus "It is a moral law that . .." is a radically hyperintensional context, to the point where it is positively misleading for the nomic primitivist to act as if she is putting forward an operator that binds propositions, some of which just happen to take the form of universally-generalized indicative conditionals. Indeed, it is not even accurate to say that the nomic primitivist is positing a primitive one-place operator. Whatever logical structure primitive moral laws have, it is a structure that partially involves the material following the phrase "It is a moral law that" in statements of moral law. That is why "It is a moral law that if ( $p$ and $q$ ), then $r$ " and "It is a moral law that if $p$, then (if $q$, then $r)$ " do not, for her, express the same moral law. The use of an embedded indicative conditional is really shorthand for a more complicated logical structure.

What, then, is that logical structure? The most elegant proposal here of which I am aware is one that Martin Glazier (2016) makes in an important recent essay. Glazier proposes that we recognize a new 
two-place sentential operator, ' $<<$ ', that is variably polyadic in its first place, that is monadic in its second place, and (this is the crucial innovation) that binds any number of variables. A general statement involving this operator is of the form " $p_{1}, \ldots, p_{m}<<_{x_{1}}, \ldots, x_{n} q$," where $x_{1}, \ldots, x_{n}$ are the bound variables. Glazier takes statements invoking this operator to express what he calls 'metaphysical laws', but we can imagine a parallel operator that is taken to express moral laws. With this operator in hand, we can then rephrase the Principle of Fidelity, as the nomic primitivist understands it, as

$\mathrm{PF}_{l}^{*} . \quad x$ breaks a promise $<<_{x} x$ is prima facie wrong,

where $x$ is taken to range over actions.

Glazier's proposal is an impressively succinct way of formalizing, in one compact notation, the generality and directionality of laws, in a way in which the nomic primitivist will need, if she is to insist on the irreducibility of moral-law operators. But there is also a striking feature to Glazier's suggestion, namely this: it is basically impossible to express his operator in natural language. Such a result would be surprising, if Glazier's hypothesis that we need his operator were correct. Natural language is like water: over time it tends to adjust itself and flow toward the metaphysically and normatively relevant cracks in nature. This is not to say that natural language is an infallible guide to metaphysical and normative reality, or to call for a return to the methodology of ordinary-language philosophy, but merely to urge caution when there is such a large disconnect between a posited fundamental feature of reality and the everyday language with which we talk about that reality.

Moreover, some of the ways in which Glazier attempts to provide an approximate gloss in English of statements involving his primitive law operator point to a more serious problem for the philosopher who would use Glazier's proposal as a way of defending Principles as Partial Grounds. ${ }^{33}$ Glazier often summarizes his proposed laws using 'makes the case'-talk, which he takes to be a "generic placeholder" that "perhaps ... should be replaced by something like 'determines' or even 'grounds' " (2016, 21, n. 15). Aping his language, we might attempt to gloss our proposed formulation of the Principle of Fidelity as follows: 34

$\mathrm{PF}_{l}^{* *}$. That an action breaks a promise makes it the case that it is prima facie wrong.

One reason this gloss is only approximate is that it doesn't fully convey the way in which the statement's generality is of a sort that is, by Glazier's lights, unique to statements of law. In other words, English doesn't mark a difference between the sort of generality featured in $\left(\mathrm{PF}_{l}^{*}\right)$ and the sort featured in a sentence such as "That an action breaks a promise is not something its agent always knows." But let us overlook that feature of the gloss and instead ask about the 'makes it the case'-locution. Although Glazier himself is non-committal about the exact import of that phrase, a theorist who would use Glazier's proposal as way of defending Principles as Partial Grounds should not be so coy: she should embrace his 'makes the case'-speech and take it, as is customary, to be another way of picking out the grounding 
relation. But then we can ask: does $\left(\mathrm{PF}_{l}^{*}\right)$ mean to invoke full or partial grounding? The former is too strong: it gives rise to the Problem of Redundant Grounding. The latter, though, is too weak: statements that pick out a single partial ground for a given sort of particular moral fact but fail to specify any of the other partial grounds that team up with that one partial ground don't quality as statements of moral law. Instead what we are looking for is a specification of all the partial grounds. So really we should be informally glossing $\left(\mathrm{PF}_{l}^{*}\right)$ as follows:

$\mathrm{PF}_{l}^{* * * *}$. That an action breaks a promise, together with this very moral law, fully makes it the case that the action is prima facie wrong.

But now disaster has struck, for this is another version of our old friend (old enemy?), $\left(\mathrm{PF}_{c}\right)$, namely the metaphysically circular version of Ross's Principle of Fidelity. Nomic primitivism plus Principles as Partial Grounds plus Glazier's operator is just a disguised version of the circularity gambit, and should be rejected for similar reasons.

The point generalizes. Let us set aside Glazier's proposal and consider, in abstract, the nomic primitivist who wishes to defend Principles as Partial Grounds. Such a theorist owes us an answer to the following question: for exactly which values of ' $\phi$ ' are sentences of the form "It's a moral law that: if an action is $\phi$, then it is wrong" true? The answer: those values which are such that, if some specific action, A, is $\phi$, then [A is $\phi$ ] and that very law together fully ground [A is wrong]. But if what primitive moral laws are in the business of doing is playing such a grounding role, then "It's a moral law that: if an action is $\phi$, then it is wrong" expresses the content of a fact whose content could just as well be expressed by saying, "I'm the sort of thing which is such that, if an action, $\mathrm{X}$, is $\phi$, then $[\mathrm{X}$ is $\phi]$ and I myself together fully make it the case that $\mathrm{X}$ is wrong." ${ }^{55}$ Thus the nomic-primitivist advocate of Principles as Partial Grounds doesn't avoid circularity; rather, she makes that circularity a primitive feature of moral laws.

A similar point applies to nomic-primitivist ways of defending Principles as Meta-Grounds and Principles as Governors. If moral laws are in the business of grounding the facts about what grounds the particular moral facts, then "It is a moral law that: if an action is $\phi$, then it is wrong" expresses the content of a fact whose content could just as well be expressed by saying, "I'm the sort of thing which is such that, if an action, $\mathrm{X}$, is $\phi$, then I myself make it the case that $[\mathrm{X}$ is $\phi]$ makes it the case that $\mathrm{X}$ is wrong." And if moral laws are in the business of governing the grounding of particular moral facts by other facts, then "It is a moral law that: if an action is $\phi$, then it is wrong" expresses the content of a fact whose content could just as well be expressed by saying, "I'm the sort of thing which is such that, if an action, X, is $\phi$, then [X is $\phi$ ] makes it the case that $\mathrm{X}$ is wrong with me as the mediating connection." But in neither case is it plausible that a fact with the sort of self-referential content at issue might play the explanatory role being posited. Self-referential facts of form

$$
\mathrm{F}^{*}=\left[\mathrm{F}^{*} \text { grounds }[\mathrm{G} \text { grounds } \mathrm{H}]\right]
$$


and

$$
\mathrm{F}^{* *}=\left[\mathrm{F}^{* *} \text { governs the grounding of } \mathrm{H} \text { by } \mathrm{G}\right]
$$

are just as problematic as self-referential facts of the form

$$
\mathrm{F}=[\mathrm{F} \text { grounds } \mathrm{G}] \text {. }
$$

\section{Is This Nomic Humeanism? And Whither Non-Naturalism?}

I end by answering the two questions in the section title. But first let me summarize where we are. I have been arguing that moral principles are not explanation-serving: they do not themselves partially explain particular moral facts, nor do they explain, govern, or in some other way mediate such first-order explanations. I also hold that moral principles are explanation-involving, so that the features they cite in their embedded conditionals or biconditionals are the grounds of the moral properties at issue. In the course of our argument against moral principles being explanation-serving, we have encountered a number of ways in which they might have a logical form that is explanation-involving, some of which employ fancy machinery such as essences, primitive moral-law operators, and metaphysical circularity. However, I think the most naive way of formulating moral principles that allows them to be explanationinvolving is also the best, namely one that uses no materials other than a wide-scope necessity operator, standard quantification, mundane indicative conditionals, and the full grounding relation, like so:

$\mathrm{PU}_{h}$. Necessarily, an action is required if and only if, and fully because, it maximizes happiness.

$\mathrm{PF}_{h}$. Necessarily, if an action breaks a promise, then that fully makes it the case that the action is prima facie wrong.

This, I put forward, is the traditional way of understanding the content of moral principles such as the Principle of Utility and of Fidelity. And in this case, the tradition is right.

Given the package of views I am putting forward, on which $\left(\mathrm{PU}_{h}\right)$ states the content of the Principle of Utility and $\left(\mathrm{PF}_{h}\right)$ the content of the Principle of Fidelity, and on which neither, if correct, plays any distinctive explanatory role with regard to particular moral facts, another question raises itself: what grounds and hence explains either of these two principles? Here I take no stand: whatever the general story is about what grounds necessity facts with contents such as the above, even when no moral or even normative properties are involved, so too do I think that general story applies to the specific case of what grounds $\left[\mathrm{PU}_{h}\right]$ or $\left[\mathrm{PF}_{h}\right]$. But on one contender for such a story, these principles, if true, will be partially grounded in facts of the form [[A maximizes happiness] fully grounds [A is required]] and [[A* breaks a promise] fully grounds $\left[\mathrm{A}^{*}\right.$ is prima facie wrong]], where $\mathrm{A}$ and $\mathrm{A}^{*}$ are individual actions performed in the actual world. So it is particular facts about the explanatory relationships between particular moral and non-moral facts that explain the general explanatory principles, rather than the other way around. Would that make the package of views being peddled in this paper the analogue for moral laws of Humeanism about scientific laws? 
In some ways "Yes," and in some ways "No." I don't wish to get embroiled in a discussion of the best way to understand nomic Humeanism, especially since this issue is complicated by the fact that its most prominent proponent of the past half-century - David Lewis - tried to formulate and defend the view without making use of any hyperintensional tools such as grounding or essence, instead attempting to make do - unsuccessfully, in my opinion - with purely intensional surrogates for those notions such as one-way supervenience. But on one natural way of understanding Humeanism about scientific laws, it is the relationship between (a) the local scientific properties of spatiotemporal entities of some specified sort at one time (or, if you prefer, on one Cauchy surface) and (b) the same properties of those same entities at later times (or, if you prefer, on different Cauchy surfaces) that is analogous to the relationship we have been focusing on between $\left(a^{\prime}\right)$ the non-moral properties of actions (and other features of the world) and $\left(b^{\prime}\right)$ the moral properties of those same actions. And here we have some similarities, but also a crucial difference. The similarities: both nomic Humeans and I (if it turns out that necessitated universal generalizations are grounded in their non-necessitated instances, which, again, I am leaving open) hold that the general laws concerning our two classes of properties are explained by patterns among the particular facts involving those properties. The crucial difference: whereas for the nomic Humean, the pattern in question is merely a pattern of co-instantiation among the properties in groups (a) and those in group (b), on the view I am advocating the pattern at issue is a pattern among particular instantiations of the grounding relation between (instantiations of) the properties in group ( $\left.\mathrm{a}^{\prime}\right)$ and (instantiations of) those in group $\left(b^{\prime}\right)$. Thus, although the view for which I have argued leaves open the possibility that moral principles are mere summaries, they would not be summaries of patterns of co-instantiation among moral and non-moral properties. Instead, they would be summaries of the particular instantiations of the grounding relation between moral and non-moral properties, where the facts about the instantiation of this relation are not themselves just a matter of the facts about the obtaining of its relata. As I understand the view, there is nothing like this in Humeanism about scientific laws: particular explanatory relations between instantiations of local scientific properties at different times that do not themselves depend entirely on the Humean mosaic are just as anathema to nomic Humeans as general explanatory relations between such properties that do not depend entirely on the Humean mosaic.

There is one final loose thread that needs tying. Earlier I said that one important motivation for accepting Principles as Partial Grounds is that such a view might seem to be forced upon non-naturalists about the normative. This was because non-naturalists are committed to

Non. There are normative facts, and at least some of them are not grounded in any fact (or plurality of facts),

and it might seem that Principles as Partial Grounds is the only way of holding onto this thesis, especially given Ross's observation that moral properties always obtain in virtue of other properties. Does this mean that if we deny that moral principles are explanation-serving and hence reject Principles as Partial 
Grounds, as I have urged we should, it follows that we must reject non-naturalism as well? If the facts about moral-and, more generally, normative- principles are not the ungrounded normative bedrock upon which all other normative facts rest, what else could possibly play this role?

To answer this question, we need to discharge an assumption I have been making throughout this essay. Rather than focusing exclusively on the moral properties of actions, let us think more generally about normative properties and relations borne by entities of all sorts. Does a generalization of Ross's observation hold for all of these properties and relations? In some cases it does seem to hold. For example, we are just are strongly inclined to hold that [Agent $\mathrm{X}$ owes it to agent $\mathrm{Y}$ that she perform action $\mathrm{A}$ ] (= a fact about the instantiation of a three-place normative relation) must obtain in virtue of other facts as we are inclined to hold that [Action A was morally required] (= a fact about the instantiation of a monadic moral property) is always grounded in other facts. But in other cases we are much less certain, especially when it is multi-place relations rather than monadic properties that are at issue. For instance, to focus on one prominent example, what about facts of the form $[$ Fact $[p]$ is a reason for agent $\mathrm{X}$ to perform action A]? Must such facts always obtain in virtue of other facts? That they might not seems very much to be a live theoretical option. While it is mystery mongering to hold that the wrongness of what I did last week is a brute fact that cannot be explained, it is not necessarily mystery mongering to hold that nothing explains why what it's like to be in agony is a reason for me to avoid future agony. But if instantiations of the reason relation can be ungrounded, then those non-naturalists who reject Principles as Partial Grounds can continue to be non-naturalists by taking (at least some) particular facts about reasons to be the ungrounded grounders of the normative realm. ${ }^{36} \mathrm{In}$ short, it is only by focusing on an overly narrow diet of examples that it might seem as if all normative properties and relations must be resultant, in Ross's sense, and hence might seem as if Principles as Partial Grounds is the only hope for non-naturalists. This, I hypothesize, is why so many non-naturalists are also reasons-firsters: it is because the reason relation is an excellent candidate for a non-resultant normative relation.

However, non-naturalists who join me in denying Principles as Partial Grounds need not be reasons-firsters, for there are other options as well. Rather than focusing on a particular type of normative fact to which all first-order normative facts can be ultimately tethered, instead we can ask about the status of the facts about this tethering relation between normative and other facts. If we continue to think of that tethering relation as the grounding relation, the question becomes: what is the status of facts of the form [Normative fact $\mathrm{N}$ obtains because facts $\mathrm{O}_{1}, \ldots, \mathrm{O}_{n}$ obtain]? Is this fact itself a normative fact? And what grounds it? Whether to classify a given fact (property, relation, etc.) as normative is itself a difficult question, but I am inclined to answer it in such a way that facts of this sort about the grounds of normative facts themselves count as normative facts. ${ }^{37}$ This would then leave the following possibility open to non-naturalists: take all first-order normative facts such as [She is required to $\phi$ ] or [He is blameworthy for having $\psi$-ed] to be fully grounded in natural facts, but take the facts about the grounds of normative 
facts to themselves be normative facts that are not grounded in natural facts - either because those grounding facts are ungrounded, or because they are grounded in normative facts that are not themselves grounded in natural facts (such as, for example, essence facts of the form [It lies in the nature of $x$ that $p$ ], where $[p]$ is normative). And we can adopt a similar strategy for other ways of understanding the tethering relation in terms of which naturalism and non-naturalism are defined: if instead it should be construed in terms of identity, then non-naturalists can take normative-natural identities of the form [[A is required $]=$ [A maximizes happiness]] to not themselves be identical to a natural fact, and so on.

This last set of possibilities is not a recherché option that exists merely as a live albeit uninhabited position in logical space. Rather, I think that almost all self-professed naturalists about the normative are unwittingly non-naturalists of this last sort. And when we add to this the first way of being a non-naturalist without endorsing Principles as Partial Grounds, the set of non-naturalists in the contemporary literature increases even more, for instead of taking facts about the instantiation of the reason relation to be the unexplained explainers of all first-order normative facts, instead we could plump for some other set of unexplained first-order explainers, such as facts about the instantiation of a fittingness relation or facts about the constitutive standards of agency. On this way of viewing things, almost all contemporary metaethical views (other than nihilism) end up counting as a form of non-naturalism about the normative, if you look hard enough for an unexplained first-order normative widget somewhere in the proposal, or for an untethered fact about the tethering of normative facts. The problem, then, is not so much how one can continue to be a non-naturalist if one denies Principles as Partial Grounds, but rather how one can avoid being a non-naturalist regardless of whether that thesis is true. ${ }^{38}$

\section{References:}

Audi, Paul. 2012. "Grounding: Toward a Theory of the In-Virtue-Of Relation.” Gournal of Philosophy 109: 685-711.

Bales, R. Eugene. 1971. "Act-Utilitarianism: Account of Right-Making Characteristics or DecisionMaking Procedure?” American Philosophical Quarterly 8: 257-65.

Bennett, Karen. 2011. "By Our Bootstraps." Philosophical Perspectives 25: 27-41.

Berker, Selim. Forthcoming. "The Unity of Grounding." To appear in Mind.

Bliss, Ricki, and Kelly Trogdon. 2016. "Metaphysical Grounding." In Stanford Encyclopedia of Philosophy, Spring 2016 edition, edited by Edward N. Zalta. <http://plato.stanford.edu/archives/spr2016 /entries/grounding/>.

Cohen, G. A. 2008. Rescuing Fustice and Equality. Cambridge, Mass.: Harvard University Press.

Dancy, Jonathan. 2004. Ethics without Principles. Oxford: Oxford University Press.

Dasgupta, Shamik. 2014. "The Possibility of Physicalism.” Gournal of Philosophy 111: 557-92.

DeRosset, Louis. 2013. "Grounding Explanations." Philosophers' Imprint 13/7: 1-26.

Enoch, David. 2011. Taking Morality Seriously: A Defense of Robust Realism. Oxford: Oxford University Press. 
Fine, Kit. 2012. "Guide to Ground." In Metaphysical Grounding: Understanding the Structure of Reality, edited by Fabrice Correia and Benjamin Schnieder, 37-80. Cambridge: Cambridge University Press.

FitzPatrick, William. 2008. "Robust Ethical Realism, Non-Naturalism, and Normativity." Oxford Studies in Metaethics 3: 159-206.

Glazier, Martin. 2016. "Laws and the Completeness of the Fundamental." In Reality Making, edited by Mark Jago, 11-37. Oxford: Oxford University Press.

- 2017. "Essentialist Explanation."

Hare, R. M. 1972. "Principles." Proceedings of the Aristotelian Society 73: 1-18.

Kagan, Shelly. 1992. "The Structure of Normative Ethics." Philosophical Perspectives 6: 223-42.

. 1998. Normative Ethics. Boulder, Colo.: Westview Press.

Leary, Stephanie. 2017. "Non-Naturalism and Normative Necessities." Oxford Studies in Metaethics 12: 76105.

Litland, Jon Erling. 2015. "Grounding, Explanation, and the Limit of Internality." Philosophical Review 124: $481-532$.

- 2017. "Grounding Ground." Oxford Studies in Metaphysics 10: 279-315.

- Forthcoming. "Could the Grounds's Grounding the Grounded Ground the Grounded?" To appear in Analysis.

Maguire, Barry. 2015. "Grounding the Autonomy of Ethics." Oxford Studies in Metaethics 10: 188-215.

McKeever, Sean, and Michael Ridge. 2006. Principled Ethics: Generalism as a Regulative Ideal. Oxford: Oxford University Press.

Raven, Michael J. 2013. "Is Ground a Strict Partial Order?” American Philosophical Quarterly 50: 193-201. . 2015. "Ground." Philosophy Compass 10/5: 322-33.

Rosen, Gideon. 2010. "Metaphysical Dependence: Grounding and Reduction." In Modality: Metaphysics, Logic, and Epistemology, edited by Bob Hale and Aviv Hoffmann, 109-35. Oxford: Oxford University Press.

—. Forthcoming. "Normative Necessity." To appear in Metaphysics, Meaning, and Modality: Themes from Kit Fine, edited by Mircea Dumitru. Oxford: Oxford University Press.

Ross, William David. 1930. The Right and the Good. Oxford: Oxford University Press.

Scanlon, T. M. 2014. Being Realistic about Reasons. Oxford: Oxford University Press.

Schaffer, Jonathan. 2016a. "Grounding in the Image of Causation." Philosophical Studies 173: 49-100.

_. 2016b. "It Is the Business of Laws to Govern." Dialectica 70: 577-88.

Shafer-Landau, Russ. 2003. Moral Realism: A Defence. Oxford: Oxford University Press.

Smith, Holly M. 1988. "Making Moral Decisions.” Noûs 22: 89-108.

Trogdon, Kelly. 2013. "An Introduction to Grounding." In Varieties of Dependence: Ontological Dependence, Grounding, Supervenience, Response-Dependence, edited by Miguel Hoeltje, Benjamin Schnieder, and Alex Steinberg, 97-122. Munich: Philosophia Verlag.

Väyrynen, Pekka. Forthcoming. "Reasons and Moral Principles." To appear in The Oxford Handbook of Reasons and Normativity, edited by Daniel Star. Oxford: Oxford University Press.

Whittle, Bruno. 2017. "Self-Referential Propositions." Synthese 194: 5023-37. 
1 See Ross 1930, 28, 79, 155 (among other places).

2 I would call this position 'particularism', but that label has already been taken for a distinct view. It is no part of the position to be defended here that there are no true moral principles, or that exceptionfree moral principles must be unsurveyably long, or that "the possibility of moral thought and judgment does not depend upon the provision of a suitable supply of moral principles" (Dancy 2004, 7).

3 I take no stand on whether my arguments generalize to laws/principles of a non-normative sort, such as physical, metaphysical, or psychophysical laws, if there be such. (We can add legal principles and rules of etiquette to this list, if it turns out that their domains are not inherently normative.) Each of these cases raises importantly different issues. But, that said, I am not adverse to accepting an analogous thesis in each case.

4 See Berker forthcoming.

5 Fine (2012, 48-50) discusses a non-factive conception of grounding, but I am skeptical that such a notion makes sense, and even if it does, it is not the notion I mean to be invoking in this essay (since we cannot use expressions such as 'because' and 'makes the case' to pick it out).

6 Thus, on this assumption, " $p$ because $q$ " is shorthand for "The fact that $p$ obtains because the fact that $q$ obtains," and "Action A has property M in virtue of having property N" is shorthand for "The fact that A has M obtains in virtue of the fact that A has N."

7 That is why taking grounding to be a relation among facts doesn't cook the books against moral anti-realists. Nihilist anti-realists should be untroubled by this assumption, since although they deny that there are any moral facts (or, if you prefer, any positive, atomic moral facts), they also deny that anything moral is grounded and that anything moral does any grounding. Constructivist anti-realists should be untroubled by this assumption, since their own view is best understood as a claim about grounding relations among facts: for example, as the claim that moral facts hold in virtue of certain facts about our attitudes. And expressivist anti-realists should be untroubled by this assumption, since most contemporary expressivists are quasi-realists who take themselves to have earned back our right to 'fact'-talk.

8 I take the labels 'unionist' and 'separatist' from Raven 2015. In the recent grounding literature, unionists include Dasgupta (2014), Fine (2012), Litland (2015), Maguire (2015), Raven (2013), and Rosen (2010), and separatists include Audi (2012), Schaffer (2016a), and Trogdon (2013).

9 See Audi 2012, 687-88; Bliss and Trogdon 2016, §4; and Schaffer 2016a, 58, 82-84.

10 Some separatists - e.g. Schaffer (2016a) - assume that if we separate grounding from explanation, then 'because' should be used to pick out explanation, not grounding. However, I see no good reason for doing so, and in fact the etymology of these words suggests otherwise. Although 'explains' has roots in the Latin expression 'explanare', meaning 'to make plain or intelligible', there are no such epistemic shades of meaning to 'because', which instead has origins in the Old French expression 'par cause de', meaning 'by reason of' or 'on account of', and hence is directly tied to many of the standard locutions used to pick out grounding. Separatists should be insisting on a division between (5) and $(1)+(2)+(3)+(4)$, not a division between $(5)+(1)$ and $(2)+(3)+(4)$.

11 See, among other places, Bales 1971; Smith 1988; McKeever and Ridge 2006, §1.2; and Väyrynen forthcoming, §3. Of course, in some cases one and the same principle might function as both a standard and a guide.

12 Or maybe we drop the wide-scope necessity operator from the content of these principles and formulate them simply as biconditionals or conditionals that as a matter of fact hold with necessity, although it is not part of their content that they do. This distinction won't matter for our purposes, so I set it to one side.

13 Or maybe we insist that although $\left(\mathrm{PU}_{i}\right)$ expresses the content of the Principle of Utility, that claim 
only qualifies as a moral principle when $\left(\mathrm{PU}_{h}\right)$ is true, and similarly for the Principle of Fidelity. This is another distinction that won't matter for our purposes.

14 See Rosen 2010, 115. Strictly speaking, we need two versions of this convention: one that stands to facts as normal quotes stand to sentences, and another that stands to facts as Quinean corner quotes stand to sentences. I allow context to make clear which of these is intended.

Also, I take it that the grammatical conventions for Rosen's brackets should parallel the grammatical conventions for quotation marks. Thus just as proper grammar dictates that the ' $\mathrm{X}$ ' in "His favorite sentence is 'Xylophones sound funny" be capitalized, so too does proper grammar dictate that the ' $\mathrm{X}$ ' in "His favorite fact is [Xylophones sound funny]" be capitalized.

15 When my meaning is clear, I sometimes use the English phrase 'the Principle of Utility' and the like in a way that leaves it ambiguous whether a sentence or a fact is denoted.

16 See Berker forthcoming, §3, for the general form of argument that I take to establish this conclusion.

17 More precisely, non-naturalists who assume - as almost all do - that there cannot be either circles or infinite, non-repeating sequences of partial ground are committed to (Non).

18 For example, either Principles as Partial Grounds or a close cousin of that thesis is assumed by Rosen (forthcoming, §7) during his investigation of a distinctively normative type of necessity; by Maguire $(2015, \S 4)$ when he proposes that we interpret Hume's claim about 'ought' and 'is' as the thesis that no ethical fact is fully grounded just in non-ethical facts; by Scanlon $(2014, \S 2.3-4)$ when he draws a distinction between pure and mixed normative claims; by Enoch $(2011, \S 6.2 .2 .1)$ during his explanation of one way in which the normative supervenes on the natural; by Cohen (2008, ch. 6) during his argument against the fact-dependence of the ultimate principles of justice; by FitzPatrick $(2008$, §8) when he insists that the goodness of an artifact partially depends on the standards of goodness for that kind of artifact; and by Shafer-Landau (2003, §1.1) during his characterization of the form of mind-dependence he calls 'stance-dependence' (although see p. 75 of that same book for a place where Shafer-Landau appears to disavow Principles as Partial Grounds, despite his earlier reliance on it).

19 Note that my objection here is not to the existence of redundant partial grounds as such. For example, I have no problem with the claim that [The ball is red] is a redundant partial ground of [Either the ball is red and round, or something is round], since it only fully grounds that disjunctive fact when taken together with another fact that suffices on its own to fully ground the disjunction. Rather, my objection is to the idea that a moral principle's special explanatory role might be a redundant one.

20 For a recent defense of self-referential propositions that could easily be extended to self-referential facts, see Whittle 2017.

21 In addition to the example I go on to consider, see Litland forthcoming.

22 Once we give up on the idea that metaphysical and normative grounding are fundamentally distinct grounding relations, then, strictly speaking, we are no longer appealing to grounding pluralism as a way of deflecting my dilemma, since grounding pluralism is best characterized in terms of the existence of at least two fundamentally distinct grounding relations, not in terms of the existence of at least two grounding relations. (That's why countenancing a distinction between partial and full grounding doesn't make one a grounding pluralist; see Berker forthcoming, §4). Nevertheless, I shall continue to call this response 'the grounding-pluralism gambit', even though the clunkier label 'the multiple-grounding-relations gambit' would probably be more apt at this stage in the dialectic.

23 What about a link that is weaker than a definitional link but still strong enough to underwrite (ii*)? I know of no plausible candidate that will do the trick here. For instance, it will not help to insist that metaphysical and normative grounding are co-determinates of some determinable dependence relation, since (a) that proposal still makes (ii*) mysterious (no other co-determinate relations interact in this way), 
and (b) there are independent objections against taking metaphysical and normative grounding to be codeterminates (see Berker forthcoming, n. 29). Nor will it help to insist that normative grounding is the determinate and metaphysical grounding the determinable, since then normative grounding would entail metaphysical grounding, and so the Problem of Redundant Grounding would return.

24 In a variant of this proposal, rather than principles being full meta-explainers, instead they are merely partial meta-explainers. (For instance, rather than the Principle of Fidelity on its own fully grounding [[A breaks a promise] fully grounds [A is prima facie wrong]], maybe the Principle of Fidelity and [A breaks a promise] together fully ground that grounding fact.) Everything I go on to say about Principles as MetaGrounds applies equally well to this variant.

25 For instance, there is a way of interpreting Shelly Kagan's (1992, 1998) influential division of normative ethics into two halves - the study of "factors" and the study of "foundations" - on which it involves a commitment to Principles as Meta-Grounds.

26 I say 'in general' because there are sneaky cases involving higher-order quantification in which indicative conditionals do ground their consequents; for instance, [If the ball is red, then the ball has a property] grounds [The ball is such that if it is red, then it has a property], which in turn grounds [The ball has a property], so by transitivity the first of these facts grounds the third. However, sneaky cases of this sort are no help in the current context. (Similar comments apply to the other two contrasts.)

27 For a sampling of the current controversies, see Rosen 2010, §13; Bennett 2011; Fine 2012, §11; deRosset 2013; Dasgupta 2014; and Litland 2017.

28 Versions of this proposal have been put forward by Rosen (2010, §13), Fine (2012, §11), and Dasgupta (2014).

$29 \quad\left(\mathbf{G}_{9}\right)$ is not without precedent in the recent metaethics literature. For instance, Leary $(2017, \S 4.4)$ commits herself to grounding claims of this form (although without claiming that the relevant essence fact constitutes a moral principle).

30 Martin Glazier (2017) argues that essence facts do their distinctive explanatory work by means of a unique form of explanation that is unconnected to grounding. I do not accept Glazier's arguments, but those who do can replace 'grounds' with 'explains grounding or explains essentialist in (Ess); that will serve my argumentative purposes equally well.

31 Nor will it do to claim that $\left[\mathrm{PF}_{e}^{*}\right]$ (= the universal essence fact) is the relevant moral principle, which then grounds $\left[\mathrm{PF}_{e}^{* *}\right]$ (= the particular essence fact), which in turn grounds [[A breaks a promise] grounds [A is prima facie wrong]] (= the particular grounding fact). Just as [It lies in the nature of conjunction that if $p \& q$, then $p$ ] fails to ground [It lies in the nature of conjunction that $p$ ], either on its own or in tandem with $\left[\begin{array}{ll}p \& & q\end{array}\right]$, so too does $\left[\mathrm{PF}_{e}^{*}\right]$ fail to ground $\left[\mathrm{PF}_{e}^{* *}\right]$, either on its own or in tandem with [A is breaks a promise].

32 Or maybe, rather than the moral-law operator itself being primitive, instead it is reducible to some other nomic operator (such as a metaphysical-law operator) that is primitive. This difference has no bearing on the arguments to come.

33 Glazier himself is not such a philosopher. He is best read as defending an analogue of Principles as Governors for metaphysical rather than moral laws, and in which 'grounding'-talk is replaced with 'explanation'-talk (so as to sidestep the separatism-versus-unionism debate).

34 Compare Glazier's $(2016,29)$ informal gloss of the metaphysical law he calls Fusion*.

35 Here I assume that playing this grounding role is the only thing moral laws are in the business of doing. A similar conclusion follows if this is part of what they are in the business of doing.

36 Note that non-naturalists who pursue this option must deny that $[[p]$ is a reason for $\mathrm{X}$ to perform A] is partially grounded in $[p]$. But I think they should deny that claim anyway, for independent reasons. 
Even though $[[p]$ is a reason for $\mathrm{X}$ to perform $\mathrm{A}]$ can only obtain if $[p]$ also obtains, this doesn't mean that the latter must partially ground the former. Compare: does $[p]$ partially make it the case that $[[p]$ is not a river] obtains? Intuitively, no.

37 At the very least, the following seems true: facts about the grounds of normative facts raise all of the metaphysical and epistemological worries that tend to motivate naturalists about a given realm of facts. So there will be just as much (or, in the eyes of non-naturalists, just as little) pressure to fully tether these facts in natural facts as there is to fully tether the first-order normative facts in natural facts. Therefore even if facts about the grounds of normative facts do not end up counting as normative, and thus naturalists about the normative are not required in letter to find an ultimate natural basis for those facts, still they seem required in spirit to do so. For this reason, I will continue to treat such grounding facts as themselves being normative in the main text, and if you want you can take my use of the phrase 'normative fact' as shorthand for 'normative-or-similarly-metaphysically-and-epistemologically-worrisome fact'.

38 Many thanks to Rachel Achs, Louis deRosset, Martin Glazier, Jed Lewinsohn, Matthew Lutz, Stephen Mackereth, Neil Mehta, Alberto Tassoni, and three anonymous referees for their written comments; to Ahson Azmat, Ralf Bader, Jeff Behrends, John Bengson, Michael Campbell, Janice Dowell, David Enoch, David Faraci, Daniel Fogal, Ned Hall, Chris Howard, Shelly Kagan, Kathyrn Lindeman, Jon Litland, Sarah McGrath, Justin Morton, Ram Neta, Susanna Rinard, Connie Rosati, Gideon Rosen, Noel Saenz, T. M. Scanlon, Keshav Singh, Sigrún Svavarsdóttir, Mike Titelbaum, Andrea Viggiano, Kate Vredenburgh, Daniel Wodak, and Alex Worsnip for discussion or correspondence; and to audiences at the University of North Carolina-Chapel Hill, the University of Southampton, and the University of Texas-Austin for their questions and comments. 